\section{NURSES IN REMOTE UNITS CAN ACCURATELY REQUEST AND INTERPRET RADIOGRAPHS}

Emergency nurse practitioners are an increasingly common feature of UK practice, with a growing body of evidence to support their safety and effectiveness. In peripheral and minor injuries units, however, the formal standing of such nurses is often less well recognised despite the fact that they have often filled this role for many years. Telemedicine has recently been advocated as a way of providing support for such remote nursing staff, but will require them to request and provisionally interpret a range of peripheral limb radiographs. In this issue we publish a study in which nurses working independently in a small unit were able to request and provisionally interpret a defined set of radiographs. A gold standard was provided by the opinions of two doctors: one seeing the patient in person and the other via a telemedicine link. This paper shows that experienced nurses, working without continuous medical supervision in a remote unit,

this issue live and online www.emjonline.com are able to request appropriate radiographs of the peripheral limbs. In addition, they are able to interpret these films to a high standard, though with a clear tendency to err on the side of caution.

See page 68

\section{EFFICACY OF MAGNESIUM SULPHATE FOR REFRACTORY VENTRICULAR FIBRILLATION}

Ventricular fibrillation resistant to defibrillation has a poor outcome. A variety of antiarrhythmic agents are recommended including lignocaine (lidocaine) and more recently amiodarone. Empirical intravenous magnesium is also suggested as a potential therapeutic agent, although evidence of a beneficial role is limited. In a powered, double blinded, randomised controlled trial empirical magnesium treatment produced a small but non-significant benefit for patients suffering a prehospital cardiac arrest. Magnesium's role as an antiarrhythmic agent for refractory ventricular fibrillation remains unclear although a large effect is very unlikely.

See page 57

\section{TREATING CHILDREN'S PAIN IN THE EMERGENCY DEPARTMENT: HOW ARE WE DOING?}

Many children present to our emergency departments every day in pain and distress. In the past five to ten years much work has been done to try and improve the standard of care for these children. This is the first in a series of four papers that provide a comprehensive review of the emergency management of children's pain. This first paper briefly explains the physiology of paediatric pain. It discusses recent publications that demonstrate that provision of pain relief to children in the emergency setting is inadequate and cites possible reasons. By exploring the reasons behind poor analgesia provision we are able to suggest some ways to improve management of children's pain. Further papers in the series will discuss specific methods of managing pain in children.

See page 4

\section{FAST TRACKING REDUCES WAITING TIMES}

Caring for minor injuries as a separate stream (often called fast tracking) has been suggested as a way of reducing waiting times in A\&E. Concerns have been expressed that it may however divert attention from those needing more urgent care. A paper in this issue looks at the effects of such a system on the waiting time of all those attending an A\&E department. The study concludes that fast tracking does reduce the waiting time of "minor" cases without delaying the care of others. This is also achieved without an increase in staffing resource. Increased consultant presence was shown to decrease the waiting time further. This study supports the expansion of a separate stream for minor injuries but further work is needed to define the optimal approach. See page 28 